\title{
Educação ambiental na Educação Básica: elementos para se pensar o trabalho da dimensão ambiental nas aulas de Educação Física
}

\author{
Jairo Antônio da Paixão*
}

\begin{abstract}
Resumo
O presente estudo analisou o trabalho da dimensão ambiental tendo como elemento mediatizador os esportes de aventura nas aulas de Educação Física em escolas púbicas na região dos Inconfidentes, MG. Uma investigação qualitativa, de caráter exploratório descritiva com 29 professores, mostrou que, a Educação Física se mostrou alheia à dimensão ambiental abordada por meio de projetos educacionais nas escolas. Está distante dos objetivos da disciplina na Educação Básica, e da conexão entre conteúdos trabalhados, ênfase para os esportes de aventura, com questões ambientais. Isso dificulta a interlocução da Educação Física com os demais componentes curriculares na efetivação de propostas interdisciplinares como o é a dimensão ambiental.

Palavras-chave: Educação Básica; Educação Física; Educação ambiental; Esporte de aventura.
\end{abstract}

\section{Environmental education in Basic Education: elements to consider the environmental dimension in Physical Education classes}

\begin{abstract}
It was analyzed the work of the environmental dimension having as a mediatizing element the adventure sports in Physical Education classes in public schools in the region of Inconfidentes, MG. A qualitative research, with a descriptive exploratory character with 29 teachers, showed that Physical Education was not aware of the environmental dimension addressed through educational projects in schools. It is distant from the objectives of the discipline in Basic Education, and the connection between content worked, emphasis on adventure sports, and environmental issues. This situation difficults the relation between Physical Education and other curricular components in the implementation of interdisciplinary proposals such as the environmental dimension.
\end{abstract}

Keywords: Basic education; Physical Education; Environmental education; Adventure sport.

\section{Introdução}

Vive-se em um tempo marcado pela égide dos avanços técnico-científicos que acarretam uma série de transformações as quais ora se confrontam ora se ajustam à sociedade de consumo. Paralelamente a esses "indícios da modernidade", percebe-se um intenso processo de degradação do meio natural. Nessa perspectiva, Bruhns (2003) destaca uma reação à modernidade - mais especificamente ao modo de vida industrial surgida na década de 1960, relacionada diretamente às formas de intervenção do homem no meio natural: o ambientalismo. Considerado um movimento social que visava, sobretudo, à preservação do meio ambiente, o ambientalismo rejeitava formas de vida industrial, particularmente o consumismo, e defendia o retorno do homem às formas simples de contato com a natureza, o resgate de rituais ancestrais, novas relações de experimentação do corpo e busca de novos paradigmas científicos e tecnológicos. No entanto, o referido movimento acabou criando uma utopia simplista por meio de grupos neorrurais, os quais acreditavam no retorno ao meio rural como solução

\footnotetext{
*Endereço Eletrônico: jairopaixao2004@ yahoo.com.br
}

ao artificialismo das grandes cidades.

Desde então, observam-se a comunhão de esforços e intenções entre as nações, com foco nas questões ambientais na busca de, sobretudo, viabilizar a adoção do tão propagado desenvolvimento sustentável. Entre os núcleos das discussões que se sucedem, destacam-se temáticas relacionadas aos impactos ambientais negativos e, consequentemente, à degradação do meio natural, a qual, indubitavelmente acarreta uma infinidade de implicações negativas para a vida do indivíduo, resultando comumente na dicotomia do binômio homem-natureza. Essa perspectiva tem norteado decisivamente o trabalho de Guattari (2006) que propõe uma articulação ético-política, a que chamou de ecosofia. Essa articulação envolveria os três registros ecológicos: o do meio ambiente; o das relações sociais; e o da subjetividade humana.

Nesses esforços, destaca-se a educação ambiental concebida entre as décadas de 1960 e 1970. Ainda que a educação ambiental não se restrinja à educação formal, cumpre assinalar que, na presente investigação, a educação ambiental é concebida como uma abordagem da Educação Básica, que se ocupa das questões naturais 
considerando as inter-relações que se estabelecem entre sociedade e natureza. Uma vez atrelada à educação formal, ressalta-se a subordinação da educação ambiental às diversas tendências pedagógicas da educação produzidas ao longo da história, que evidencia um longo processo que se iniciou a partir de uma perspectiva tradicional e, ao que tudo indica, encontra-se numa perspectiva crítica de ensino. Desta forma, Medina (2000) conclui que, ao longo desse processo, a educação ambiental se fez valer dos elementos positivos dos diversos enfoques das tendências pedagógicas para um fazer educacional mais pertinente.

Tendo em vista, a vigência da perspectiva crítica da educação, é possível afirmar que a educação ambiental vem-se ancorando na vertente socioambiental. Trata-se de uma vertente critica que, ao contrário das perspectivas anteriores, reintegra o homem na natureza, como espécie biológica com características específicas (LEFF, 1991; NOVO, 1989). Conforme ressaltam os autores, a vertente socioambiental não possui um currículo preestabelecido, o que possibilita a sua integração ao projeto político pedagógico, bem como aos diversos componentes curriculares. Tal vertente pretende favorecer uma educação integral e integradora, que atinja as necessidades cognitivas, afetivas e de geração de competências para uma atividade responsável e ética do indivíduo como agente social comprometido com a melhoria da qualidade de vida.

Cumpre destacar que, do ponto de vista legal, introduziu-se a dimensão ambiental na educação formal a partir de uma exigência da LDB/96 por meio do tema transversal Meio Ambiente contido nos Parâmetros Curriculares Nacionais no currículo dos segmentos que compõem a Educação Básica (BRASIL, 1998). Nas palavras de Darido et al. (2001), tais temas denominam-se temas transversais, pois, devem ser trabalhados por todos os componentes curriculares, logo, pode-se interpretá-los como se fossem as ruas principais do currículo escolar que necessitam ser atravessadas por todas as disciplinas. Não obstante, buscam-se desenvolver processos de sensibilização em relação à questão ambiental através de atividades planejadas que permitam uma progressiva inserção nos meios local, regional e nacional e internacional. Esses processos devem responder aos interesses e às motivações dos alunos, propiciando-lhes aquisição de conhecimentos científicos e técnicos, e atitudes éticas para que possam participar de modo eficaz na gestão dos processos de desenvolvimento sustentável de sua comunidade (MEDINA; SANTOS, 1999; LEFF, 1991).

Tendo em vista o caráter transversal atribuído à educação ambiental na educação formal, a Educação Física configura-se como uma área do conhecimento que possibilita, juntamente com as demais disciplinas, a oportunidade de se desenvolver de maneira interdisciplinar conhecimento relacionado à dimensão ambiental. Isso porque, nomeadamente, a Educação Física se apresenta como componente curricular por que os alunos demonstram grande interesse (BRANDOLIN, 2010; ALMEIDA et al., 2011). Tal interesse e, em alguns casos, a predileção por parte dos alunos, relaciona-se diretamente com a especificidade desse componente curricular como o espaço físico em que, geralmente, são realizadas as aulas, o movimento como eixo norteador dos conteúdos trabalhados, somado à sensação de liberdade vivenciada pelos alunos. Os Parâmetros Curriculares Nacionais recomendam a Educação Física que extrapole suas atividades curriculares, e que vise à construção de uma escola comprometida com a transformação social que favoreça o conhecimento crítico da realidade (BRASIL, 1998).

Não obstante, dentre os conteúdos tematizados pela Cultura Corporal de Movimento ${ }^{1}$, comumente tratados nas aulas de Educação Física, como os jogos, as ginásticas, as lutas, as danças e os esportes, insere-se o esporte de aventura como uma das vertentes desse último. Do ponto de vista legal, trata-se de uma situação que se confirma na Base Nacional Comum Curricular, na qual o esporte de aventura, ora definido Práticas Corporais de Aventura, insere-se como unidade temática no rol dos conteúdos a serem tratados nas aulas de Educação Física. Tendo em vista o repertório de conteúdos tradicionalmente tematizados nesse componente curricular, pode se dizer tratar de uma novidade em termos de ordenamento legal relacionada à Educação Física escolar brasileira (BRASIL, 2017). Vale ressaltar que dentre as finalidades atribuídas à referida prática corporal, na formação dos alunos, a Base Nacional Comum Curricular faz menção aos aspectos relacionados à dimensão ambiental.

Dada as suas especificidades, trata-se de uma vertente esportiva que apresenta um conjunto de características que muito propicia o trabalho com as questões ambientais. Essas práticas corporais de aventura vivenciadas nos diferentes ambientes naturais caracterizam-se pela interação de seus 
praticantes nos distintos segmentos que compõem o meio natural, como aquelas praticadas na água, na terra, no gelo ou no ar. Ainda que permeadas pelas contradições e limitações, as diversas modalidades que compõem o esporte de aventura na natureza apresentam-se como um poderoso aliado no trabalho da educação ambiental, num processo cujo ponto de partida se dará pela reestruturação do binômio homem-natureza.

Dado ao fato dessas práticas corporais ocorrerem em diferentes ambientes naturais e pela emergência atual que vem demandando as questões ambientais, têm-se reunidos subsídios suficientes para se pensar uma abordagem da dimensão ambiental no contexto da Educação Física escolar conjuntamente com outras áreas do conhecimento que compõem o currículo da Educação Básica. Com base no tema transversal Meio Ambiente, contido nos Parâmetros Curriculares Nacionais - torna-se possível a transmissão de comportamentos de respeito e de preservação do meio natural, bem como da aprendizagem e vivências diferenciadas do esporte convencional nas modalidades como futsal, vôlei, basquete e handebol que ainda mantêm sua hegemonia nas aulas de Educação Física escolar no país. Conforme salientam Paiva e Franca (2007) e Guimarães et al. (2007), incluem-se ainda, no trabalho do esporte de aventura, discussões quanto à sustentabilidade, reutilização de materiais, impactos ambientais, oportunizando os alunos a refletirem e debaterem sobre os preceitos da educação ambiental.

Assim, ressalta-se que a organização didático-pedagógica de um determinado conteúdo neste caso, ênfase nas modalidades de esporte de aventura, irá demandar do professor domínio de conhecimentos e habilidades que se configuram no processo de ensino e de aprendizagem e, por conseguinte, o trabalho do tema transversal meio ambiente. No entanto, ao se considerar propostas de ensino e/ou mesmo projetos interdisciplinares na escola envolvendo o esporte de aventura como conteúdo, alguns fatores surgem como contraponto, tais como o despreparo de uma parcela significativa de professores de Educação Física para implantar e avaliar as atividades de aventura que pode inibir o pleno desenvolvimento deste conteúdo nas aulas, além do custo elevado de alguns equipamentos específicos para a prática de determinadas modalidade (SOARES; PAIXÃO, 2010). Conquanto, dentre as diversas modalidade de esporte de aventura, destacam-se aquelas que não requerem equipamentos específicos, o que por sua vez, facilita sua inclusão em meio escolar, tais como o trekking, as corridas de orientação, o skate, as caminhadas ecológicas, entre outras, pelo fato de serem atividades esportivas que se adaptam bem à realidade da maioria das escolas públicas brasileiras.

A partir das asseverações que envolvem a escola, o professor, a Educação Física e as implicações no desenvolvimento do conteúdo esporte de aventura na natureza e tendo em vista as questões ambientais, o presente estudo teve como objetivo analisar o trabalho da dimensão ambiental tendo como elemento mediatizador o conteúdo esporte de aventura, nas aulas de Educação Física em escolas da rede pública, localizadas em cidades (Catas Altas, Itabirito, Mariana e Ouro Preto) que compõem a região dos Inconfidentes no estado de Minas Gerais.

\section{Metodologia}

Este estudo caracteriza-se como pesquisa qualitativa de natureza descritivo-exploratória (THOMAS; NELSON; SILVERMAN, 2012) que tem como características observar, registrar, analisar, descrever, correlacionar fatos ou fenômenos sem manipulá-los, procurando, assim, descobrir com precisão a frequência com que o fenômeno ocorre e sua relação com outros fatores.

Como instrumento de coleta de dados, foi empregado um questionário contendo 16 itens estruturados a partir dos pressupostos teóricos da literatura especializada. $\mathrm{Na}$ operacionalização das variáveis contidas nos itens, o questionário foi estruturado a partir da escala Likert de 5 pontos em que era permitido ao informante marcar uma alternativa $(1=$ discordo plenamente; $2=$ discordo; $3=$ indiferente; $\quad 4=$ concordo; $\quad 5=$ concordo plenamente) em ordem de importância, tendo em vista a percepção dos professores participantes do estudo (FEHRING, 1987). Para fins de análise e discussão dos resultados, as categorias 1 e 2 foram consideradas negativas, a 3 neutra e as categorias 4 e 5 positivas. Este escalonamento justifica-se, uma vez que, não raro, as pessoas são motivadas a realizar uma ação ou a adotar algum tipo de procedimento a partir de um conjunto de concepções de mundo, valores e de saberes oriundos de vivências ao longo de sua trajetória de vida e/ou profissional, podendo, desta forma, atribuir maior peso a um determinado aspecto a outros, embora todos possam ser importantes.

O grupo amostral foi constituído de 29 
professores licenciados em Educação Física (18 homens e 11 mulheres), com idade média de 34 anos (que vai de 21 a 55 anos), atuantes em escolas localizadas em 4 cidades (Catas Altas, Itabirito, Mariana e Ouro Preto) que compõem a região dos Inconfidentes em Minas Gerais, no estado de Minas Gerais. A escolha foi intencional, pois além de se tratar de uma região que, do ponto de vista histórico-cultural, possui representatividade na história de Minas Gerais, tem proximidade com a cidade de Ouro Preto e a Universidade. Aliado a esses fatores, encontrava-se a necessidade de delimitar a amostra.

Para a coleta de dados, o referido instrumento foi inserido em formulário no Google Drive (https://drive.google.com/), estruturado a partir de uma mensagem inicial com informações básicas sobre a pesquisa, links de acesso ao instrumento de coleta de dados e ao TCLE na íntegra, bem como o endereço eletrônico do pesquisador reponsável, caso se fizesse necessário o contato por parte dos participantes.

Dentre os procedimentos adotados na definição do grupo amostral, foram estabelecidos contatos com a Superintendência Regional de Ensino da cidade de Ouro Preto, que forneceu a relação de todas as escolas de Educação Básica localizadas nas cidades de Catas Altas, Itabirito, Mariana e Ouro Preto. Dessa forma, por meio de contatos telefônicos com as secretarias das respectivas escolas foi feito o levantamento de informações sobre os professores de Educação Física que se encontravam vinculados às mesmas. $\mathrm{Na}$ impossibilidade de obtenção de algumas informações acerca dos professores, eram agendadas novas chamadas para que as informações pudessem ser confirmadas nas documentações existentes nas escolas e, em alguns casos, diretamente com os professores.

Os critérios de inclusão foram professores licenciados em Educação Física que atuavam no magistério nas escolas da rede pública municipal e estadual das referidas cidades que compõem a região dos Inconfidentes, MG; a leitura do Termo de Consentimento Livre e Esclarecido (TCLE) na mensagem convite (Google Drive); a concordância com os termos da pesquisa; e o interesse em participar dela. Visando assegurar uma amostra representativa para o presente estudo, optou-se pela amostragem acidental por saturação que, de acordo com Becker (1994), trata-se de técnica recomendada para definir a representatividade do grupo. Nesse sentido, o ponto de saturação deu-se a partir do momento em que as respostas começaram a se tornar repetitivas, revelando dados suficientes para atender ao objetivo da investigação. Somou-se a esse fato, o período definido para a coleta de dados no cronograma de atividades da pesquisa que compreendeu setembro a novembro de 2015.

O material resultante da coleta de dados foi organizado a partir dos itens que constituiam os questionários tendo em vista a escala Likert de 5 pontos e a recorrência em que as respostas foram emitidas. Foi empregada análise estatística descritiva simples. Assim, os dados foram organizados em três tabelas apresentadas na seção resultados e discussão.

No decorrer do processo de condução da presente pesquisa, foram respeitadas as diretrizes regulamentadas pela Resolução $n^{\circ}$ 466/2012 do CONEP, sendo o projeto aprovado pelo Comitê de Ética em Pesquisa da Universidade Federal de Ouro Preto, ofício CEP $\mathrm{N}^{\circ} 382.868$, de 26 de agosto de 2015.

\section{Resultados e discussão}

A análise instaurou-se a partir da triangulação entre os dados coletados com os professores de Educação Física, o referencial teórico especializado e, também, as posições assumidas pelos autores da investigação. Desta forma, foi possível a compreensão e discussão das categorias que tiveram o conteúdo esporte de aventura, a educação ambiental, a prática pedagógica e a Educação Física escolar como eixos norteadores. Essas categorias encontram-se organizadas em duas partes: a primeira analisa o conteúdo esporte de aventura e suas possibilidades nas aulas e, a segunda aborda o desenvolvimento de práticas pedagógicas nas aulas de Educação Física. 


\section{O conteúdo esporte de aventura e suas possibilidades nas aulas}

TABELA 1: O conteúdo esporte de aventura nas aulas de Educação Física

\begin{tabular}{|c|c|c|c|c|c|}
\hline \multirow[t]{2}{*}{ VARIÁVEIS CONSIDERADAS } & \multicolumn{5}{|c|}{$\begin{array}{l}\text { ESCALA DE LIKERT } \\
(\%)\end{array}$} \\
\hline & 1 & 2 & 3 & 4 & 5 \\
\hline $\begin{array}{l}\text { O esporte de aventura é uma prática corporal bem difundida nos diferentes } \\
\text { contextos sociais. }\end{array}$ & -- & 14 & -- & 37 & 49 \\
\hline $\begin{array}{l}\text { Geralmente o professor de Educação Física apresenta conhecimento teórico- } \\
\text { prático acerca de determinadas modalidades de esporte de aventura. }\end{array}$ & 31 & 38 & 7 & 10 & 14 \\
\hline $\begin{array}{l}\text { O esporte de aventura é uma vertente esportiva que apresenta potencial para ser } \\
\text { trabalhado nas aulas de Educação Física. }\end{array}$ & 21 & 24 & 10 & 14 & 31 \\
\hline $\begin{array}{l}\text { O esporte de aventura possibilita desenvolver aspectos teórico-práticos da } \\
\text { educação ambiental na escola. }\end{array}$ & -- & -- & -- & 31 & 69 \\
\hline $\begin{array}{l}\text { As escolas apresentam infraestrutura que permite o trato de determinadas } \\
\text { modalidades de esporte de aventura. }\end{array}$ & 79 & 21 & -- & -- & -- \\
\hline $\begin{array}{l}\text { Os alunos demonstram interesse em participar das aulas voltadas a abordar o } \\
\text { conteúdo esporte de aventura. }\end{array}$ & -- & -- & 14 & 55 & 31 \\
\hline
\end{tabular}

Nota: $\mathbf{1}=$ Discordo plenamente; $\mathbf{2}=$ Discordo; $\mathbf{3}=$ Indiferente; $\mathbf{4 = C o n c o r d o ; ~} \mathbf{5}=$ Concordo plenamente

Fonte: Elaborado pelo autor

A partir da transição paradigmática da modernidade para a pós-modernidade, surgem novas práticas corporais, entre elas o esporte de aventura na natureza. Trata-se de uma vertente esportiva que elegeu os diferentes ambientes naturais como o terrestre, o aéreo e o aquático como locus privilegiado para a sua manifestação (BETRÁN; BETRÁN, 1995). Atualmente, é possível afirmar que as diferentes modalidades de esporte de aventura configuram-se como uma realidade, ocupando um espaço considerável nos meios midiáticos seja na perspectiva do lazer ou competição (PAIXÃO et al., 2011). Nessa direção, é importante assinalar que os resultados obtidos mostram que a maioria dos professores de Educação Física atuante na Educação Básica (86\%) coaduna com essa situação apontada nos estudos na área. Dentre os fatores que têm contribuído para ampliar a difusão dos esportes de aventura nos meio social, ganham relevo diferentes fatores como a necessidade do homem afastar-se do estresse das grandes cidades; a ruptura com os esportes convencionais olímpicos e aqueles veiculados pelo esporte espetáculo; a retomada do espírito aventureiro que encaminha o homem a um ambiente selvagem, carregado de incertezas, a íntima ligação com a lógica atual da sociedade, que interage diretamente com o aumento da incerteza política, econômica, social e cultural e a emergência de um sentimento ecológico e de preservação da natureza como condição de sobrevivência no planeta (PAIXÃO, 2012).

Não obstante, apesar de alguns matizes que destacam o esporte de aventura como prática corporal que estabelece interface com diferentes aspectos, inclusive aqueles relacionados à dimensão ambiental, uma parcela significativa dos participantes $(69 \%)$ alude à falta de conhecimento teórico-prático acerca do conteúdo deste esporte. Tal situação apresenta um conjunto de implicações que certamente vem comprometendo a seleção do esporte de aventura como conteúdo a ser contemplado nas aulas. A representatividade que vem alcançando esse esporte na sociedade atual sinaliza a importância do referido conteúdo, bem como a sua inclusão nos currículos da educação formal. Isso porque, as modalidades de esporte de aventura podem oportunizar vivências capazes de contemplar os princípios propostos pela Cultura Corporal de Movimento, apresentando-se como um 

nas aulas de Educação Física

tema de grande relevância e abrangência para o desenvolvimento de temáticas nas aulas de Educação Física como o tema transversal meio ambiente.

Toda e qualquer proposta que envolva a inserção de novas temáticas no âmbito da escola, como é o caso dos esportes de aventura, suscita para além de uma consonância com os princípios almejados no projeto político pedagógico da escola, passa indubitavelmente pela necessidade de serem precedidas de reflexões a partir do conceito de conteúdo. Nessa perspectiva, o entendimento de conteúdo leva, de forma irremediável, à consideração das dimensões que permeiam o processo ensino aprendizagem de um dado conteúdo como a dimensão conceitual, atitudinal e procedimental (COLL et al., 2000; DARIDO; RANGEL, 2005). Como conteúdo da Educação Física escolar, o esporte de aventura leva às referidas dimensões.

Desta forma, a dimensão conceitual referese ao que o aprendiz deverá aprender em termos de conceitos e fatos relacionados a determinado conteúdo, como por exemplo: compreender a evolução das modalidades de esporte de aventura como possibilidade de lazer e competição na natureza, contextualizar as modalidades existentes, enfocando, por exemplo, sua evolução, potencialidades e possíveis impactos no meio natural na contemporaneidade; conhecer as diferentes denominações atribuídas às atividades de aventura e especificidades para a sua prática em diferentes ambientes naturais; e perceber as práticas de aventura, no meio natural, como espaço para diferentes manifestações expressivas humanas, bem como os aspectos relacionados à dimensão preservacionista dos diferentes ambientais naturais como aéreo, aquático e terrestre.

A dimensão procedimental diz respeito ao que se deve saber fazer diante de uma situação concreta da prática de um determinado conteúdo, como: executar os procedimentos específicos de uma modalidade de aventura e relacioná-los com fatores de ordem cultural, social e emocional ligados a ela; vivenciar fortes emoções, vertigem, sensação do risco e adrenalina propiciados pela prática de uma modalidade nos diferentes ambientes naturais em que se efetiva; e adquirir os princípios essenciais para a prática de uma modalidade, como procedimentos de segurança, utilização correta de equipamentos, entre outros. E, por fim, a dimensão atitudinal refere-se ao que se deve ser, efetivada pela atitude do indivíduo em seu meio. Tem-se a compreensão da natureza numa perspectiva que ultrapassa a visão de simples cenário no qual ocorrem as atividades de aventura, mas também na urgência de valores e atitudes no sentido de preservá-la como bem comum; respeitar os limites corporais quando na realização das práticas físicas de aventura no meio natural; e vivenciar as modalidades tendo como princípios balizadores da prática atitudes de interação, solidariedade e companheirismo.

Ainda que os professores de Educação Física não detenham o conhecimento teórico-prático acerca do esporte de aventura para ser abordado como um conteúdo nas aulas, por outro lado, esses mesmos professores afirmam reconhecer o potencial do esporte de aventura enquanto conteúdo que, por sua vez, possibilita a abordagem da dimensão ambiental nas aulas de Educação Física numa perspectiva da educação ambiental na educação formal.

Diante do cenário que os dados revelam, vale ressaltar que o professor é o elemento mais significativo para concretizar o meio, as estratégias de ensino e os recursos educativos dentro de um determinado contexto de ensino aprendizagem. Ele, com suas crenças e atitudes, determinará as possibilidades que pode desenvolver no contexto educativo. Essa situação fornece pistas para se considerar a formação inicial como um dos possíveis fatores que contribuem para o desconhecimento por parte do professor para determinados temas propostos pela Cultura Corporal de Movimento como conteúdos a serem trabalhados nas aulas de Educação Física escolar.

Ainda, os professores reconhecem existir interesse por parte dos alunos em participar de atividades relacionadas ao esporte de aventura nas aulas. Tendo em vista as características e especificidades contidas nas diversas modalidades que compõem o esporte de aventura, adoção dessa modalidade pelo professor, como conteúdo nas aulas, tende a estimular nos alunos a vontade em participar das aulas, criando novos desafios e favorecendo a relação interpessoal entre eles. Além disso, pode gerar benefícios como a elaboração de conhecimento através da expressão corporal, autoconfiança, superação de limites, companheirismo e fomento à educação ambiental (PEREIRA; CARVALHO; RICHTER, 2008).

De acordo com os professores considerados neste estudo, a escola não apresenta infraestrutura para o trabalho do conteúdo esporte de aventura. Em conformidade com investigações que se voltam 
à prática pedagógica do professor, a escola, principalmente aquelas que integralizam as redes públicas de ensino, tem mostrado, como ponto comum, a falta de estrutura física adequada para a condução de diferentes ações didáticas pedagógicas. No caso da Educação Física, que demanda um espaço diferenciado devido à sua especificidade como componente curricular, tal cenário parece mostrar um descaso ainda maior.

Com relação ao esporte de aventura, reconhecidamente, muitas modalidades demandam materiais específicos para a referida prática, o que pode dificultar sua execução durante as aulas de Educação Física na escola (TAHARA; CARNICELLI FILHO, 2013; TAHARA; DARIDO, 2016). Por outro lado, outras modalidades são bastante simples em sua essência, como é o caso do trekking, a corrida de orientação, o sandboard, entre outros, o que facilita sua inserção entre os educandos, independente de seus contextos socioculturais (TAHARA; DARIDO, 2016). Os autores apresentam sugestões de trabalho como a realização do trekking próximo ao entorno escolar, confecção de bússolas, criação de mapas enigmáticos e depois a realização de uma corrida de orientação dentro da própria escola ou, até mesmo, a utilização de caixas de papelão para simbolizar pranchas e descer pequenas elevações de terra ou areia, fazendo alusão ao sandboard, entre outras maneiras bem simples para vivenciar e conhecer algumas modalidades de aventura.

\section{Práticas pedagógicas nas aulas de Educação Física}

As práticas pedagógicas do professor no ambiente de intervenção na educação formal, uma vez fundamentadas na perspectiva crítica de ensino, comumente conduzem a processos de ensino aprendizagem que favorecem a aprendizagem significativa na qual se inserem princípios de ensino como o da individualização, da criatividade, da inclusão, da autonomia, e da socialização. No caso específico da presente investigação, o objeto de estudo considerou o desenvolvimento das práticas pedagógicas do professor nas aulas de Educação Física que, fazendo valer do conteúdo esporte de aventura, possa mediar o trabalho dos aspectos ambientais, na perspectiva da educação ambiental. Os resultados desta categoria de análise encontramse na Tabela 2.

TABELA 2: Práticas pedagógicas nas aulas de Educação Física

\begin{tabular}{|c|c|c|c|c|c|}
\hline \multirow[t]{2}{*}{ VARIÁVEIS CONSIDERADAS } & \multicolumn{5}{|c|}{$\begin{array}{c}\text { ESCALA DE LIKERT } \\
(\%)\end{array}$} \\
\hline & 1 & 2 & 3 & 4 & 5 \\
\hline \multicolumn{6}{|l|}{ A adoção de abordagens pedagógicas de perspectiva crítica nas aulas de } \\
\hline $\begin{array}{l}\text { Educação Física é uma situação amplamente definida entre os professores } \\
\text { da área. }\end{array}$ & 59 & 21 & 7 & 13 & -- \\
\hline $\begin{array}{l}\text { No planejamento das aulas e atividades curriculares empregam-se } \\
\text { documentos oficiais como PCN's, CBC e outras propostas curriculares. }\end{array}$ & 21 & 38 & 7 & 21 & 13 \\
\hline $\begin{array}{l}\text { A Educação Física mantém estreito diálogo com os demais componentes } \\
\text { curriculares da Educação Básica na escola. }\end{array}$ & 56 & 24 & 10 & 10 & -- \\
\hline $\begin{array}{l}\text { Geralmente os temas transversais são trabalhados na perspectiva } \\
\text { interdisciplinar por meio de projetos na escola. }\end{array}$ & -- & 21 & 17 & 35 & 27 \\
\hline $\begin{array}{l}\text { Geralmente o tema transversal meio ambiente é trabalhado nas aulas de } \\
\text { Educação Física dialogando com outros componentes curriculares. }\end{array}$ & 41 & 38 & -- & 17 & 4 \\
\hline
\end{tabular}

Nota: $\mathbf{1}=$ Discordo plenamente; $\mathbf{2}=$ Discordo; $\mathbf{3}=$ Indiferente; $\mathbf{4 = C o n c o r d o ; ~} \mathbf{5}=$ Concordo plenamente

Fonte: Elaborado pelo autor 
Tendo em vista o processo de inserção da Educação Física na escola, seus objetivos e entendimentos para um dado momento histórico, relacionar Educação Física escolar e prática pedagógica era algo que não fazia parte do imaginário de professores, alunos, e da escola de uma maneira geral. Durante muito tempo, a Educação Física foi pensada e conduzida não como um componente curricular, e sim como uma mera atividade descolada do contexto escolar. Os próprios professores não se viam como professores e sim técnicos ou treinadores dos alunos. Essa situação foi se alterando a partir da primeira metade da década de 1990 com o surgimento das propostas pedagógicas críticas para o ensino da Educação Física, Parâmetros Curriculares Comum (PCN's), Conteúdo Básico Comum (CBC) e propostas curriculares por Estado ou região (SOARES et al., 1992).

Em conformidade com a maioria $(80 \%)$ dos professores participantes dessa investigação, a adoção de abordagens pedagógicas críticas pelos professores de Educação Física nas aulas está longe da realidade.

Cumpre destacar que, após mais de três décadas do movimento renovador da Educação Física, parece prevalecer, no cenário atual, acentuado distanciamento entre os pressupostos teórico-metodológicos - principalmente aquelas que buscam fundamentação nas ciências humanas, como a Sociologia e Filosofia da Educação - e a efetivação de uma prática de intervenção no trabalho com os conteúdos dessa disciplina (SOARES, 2010). Essa situação apresenta-se de forma coerente quando se analisam os procedimentos relacionados ao planejamento das práticas pedagógicas, visto que uma parcela significativa (59\%) reconhece a não consideração de documentos oficiais na tarefa de planejar suas aulas. Esse achado fornece pistas para se refletir sobre a possível prevalência da perspectiva biologicicista tecnicista (GHIRALDELLI JÚNIOR, 2007) o que, por sua vez, desconsidera, muitas vezes, os aspectos histórico-culturais presentes nas práticas corporais de movimento (SOARES et al., 1992).

Convém sublinhar que as abordagens pedagógicas críticas da Educação Física pretendem combater os vieses para o ensino dos temas sugeridos pela Cultura Corporal de Movimento, com visão mais equilibrada dos processos de ensino e aprendizagem que concebem a Educação Física como um componente curricular e o seu papel coadjuvante junto aos demais componentes que levam à formação de um sujeito dotado de postura crítica e autônoma. Tal postura deverá transcender o período que compreende a Educação Básica para os conteúdos contemplados nessa fase de formação.

Faz-se importante retomar Medina (2000) quando afirma que, ao longo de seu processo de implementação, a educação ambiental se fez valer dos elementos positivos dos diversos enfoques das tendências pedagógicas para um fazer educacional mais pertinente.

Ao analisar a educação ambiental sob a influência das diferentes abordagens pedagógicas da educação, percebe-se um crescente movimento no qual ela se apropriou de um conjunto de condicionantes como o social, o histórico e o econômico sem os quais, se torna inconcebível compreender as questões ambientais, bem como a apropriação do conhecimento historicamente acumulado e sistematizado pelas diferentes ciências, como instrumento necessário para se lançar as bases para transformações. Vale lembrar que esses elementos são proposições advindas exclusivamente de abordagens críticas de ensino na educação formal.

A não prevalência de abordagens pedagógicas críticas no âmbito da Educação Física escolar, tendo em vista os professores considerados nesta investigação, é um fato que demanda atenção no meio acadêmico. Ao se idealizar o trabalho da dimensão ambiental nas aulas, não se pode negar que o contato com a natureza, através das modalidades de esporte de aventura, apresenta um viés positivo e outro negativo. Por um lado, pode, por exemplo, aumentar a consciência ecológica dos envolvidos com a prática esportiva, pode inibir a ação predatória em seus locais de prática e contribuir para a melhoria da qualidade de vida. No entanto, quando não planejadas, essas mesmas práticas esportivas podem interferir negativamente nos fatores ambientais, podendo ocasionar danos aos ambientes onde são praticadas. Costa (2000) menciona que, embora divulguem que essas práticas junto à natureza são preservacionistas, pode haver um desequilíbrio nos ecossistemas devido à construção de infraestrutura de apoio à sua realização. Acrescenta-se ainda a poluição sonora e ambiental, lixo, devastação e erosão nos locais utilizados para a prática. Essas questões precisam ser devidamente problematizadas pelo professor nas aulas.

Tal procedimento pedagógico é premissa das abordagens críticas da Educação Física como a Crítico Superadora (SOARES et al., 1992), Crítico 
Emancipatória (KUNZ, 2003) e Concepções do Ensino Aberto (HILDEBRANDT-STRAMANN, 2009). Sobretudo, a relação do aluno com o conteúdo não é direta na realidade, mas sim através de algum meio, recursos educativos e/ou estratégias de ensino que representem, aproximem ou facilitem o acesso desse aluno numa perspectiva que vai desde o mero reprodutivismo até mesmo à apreensão de um dado conteúdo. É importante assinalar que os meios, os recursos educativos e/ou estratégias de ensino vinculam diretamente à uma abordagem pedagógica.

Soma-se a essa situação, o distanciamento pedagógico que ainda parece prevalecer entre a Educação Física e os demais componentes curriculares na escola. Isso é confirmado pela maioria $(80 \%)$ dos professores.

Conforme já assinalado, a Educação Física apresenta determinadas especificidades se comparada com os demais componentes curriculares na escola. Trata-se de uma área do saber que tem como objeto de estudo o movimento humano mediatizado pelas diferentes práticas corporais e culturais, que se efetivam em ambientes que não se restringem às salas de aulas. No entanto, essa mesma especificidade leva a interpretações equivocadas sobre a Educação Física, tanto por alunos quanto pelos próprios professores com formação na referida área. Em alguns casos, a disciplina chega a ser percebida e mesmo trabalhada como eminentemente prática (DARIDO; RANGEL, 2005) e, em outros casos, como meros momentos de lazer em que o aluno se encontra totalmente livre para fazer o que desejar (BARBOSA, 2001). Por vezes, decorre daí, um entendimento de que a Educação Física não se encontra inserida na escola como componente curricular, e sim como uma mera atividade de natureza prática. Partindo-se das possibilidades de transformações apontadas pelo movimento renovador, vivenciado no âmbito educacional na segunda metade da década de 1980, González e Fensterseifer (2009) afirmam que o movimento renovador significou, sobretudo, a incorporação de questionamentos teóricopedagógicos para o campo da Educação Física, dando relevo à necessidade de reinventar o seu espaço na escola como componente curricular da Educação Básica.

Cumpre destacar que o trabalho da dimensão ambiental na educação formal requer, sobretudo, procedimento integrado entre as diferentes áreas do conhecimento, haja vista a expressiva relevância social que o tema impõe na sociedade atual. E não é demais repetir que a questão ambiental se insere na Educação Básica a partir do tema transversal meio ambiente assim definido nos Parâmetros Curriculares Nacionais: "[...] os conteúdos de meio ambiente serão integrados ao currículo através do que se chama transversalidade, isto é, serão tratados nas áreas de conhecimento de modo a impregnar toda prática educativa [...]" (BRASIL, 1998, p.42). Por assim dizer, o distanciamento pedagógico da Educação Física com relação aos demais componentes curriculares configura-se como um fator que implica negativamente no seu envolvimento em propostas de caráter transdisciplinar, uma vez que essa disciplina deve se inserir nos projetos educativos estando integrada à proposta pedagógica da escola, assim como preconiza a nova Lei de Diretrizes e Bases da Educação (BRASIL, 1996).

Não obstante, ainda que o tema transversal meio ambiente seja tratado numa perspectiva transdisciplinar nas escolas em que se vinculam profissionalmente os participantes dessa investigação, segundo a maioria desses professores $(79 \%)$, a Educação Física não estabelece interlocução com as demais áreas no desenvolvimento de projetos escolares que abordam a dimensão ambiental. Conforme afirma Yus (1998), quando se selecionam temas transversais a serem trabalhados na escola, como, por exemplo, na educação ambiental, deve-se se atentar que os sujeitos da educação são pessoas integradas, considerando as ações e valores éticos envolvidos.

Nesta perspectiva que sinaliza estratégias educativas para o trabalho das questões ambientais na Educação Básica, é possível afirmar que a Educação Física integrada às demais áreas do conhecimento tem muito a contribuir. As intervenções nas aulas de Educação Física, bem como nos eventos temáticos orientados para as questões relacionadas ao meio ambiente se mostram como um caminho possível para a condução do trabalho. Como afirmam acertadamente Darido et al. (2001), impõe-se a necessidade de se expandir o conceito de espaço durante as aulas; espaço este que passa a ser enxergado sob as dimensões dos elementos naturais constitutivos e sociais. Outro ponto que merece destaque, no trabalho da questão ambiental pela Educação Física, é a necessidade de se vivenciar situações práticas em ambientes diferenciados como parques, praças, praias, clubes e outros a fim de se estabelecer comparações com a realidade vivida no dia-a-dia. 


\section{Considerações finais}

A partir dos resultados obtidos, neste estudo, e considerando as suas limitações metodológicas, é possível afirmar que os aspectos relacionados ao trabalho da dimensão ambiental nas aulas de Educação Física distanciam-se de projetos educacionais desenvolvidos na escola que tem como enfoque a educação ambiental. Dentre os fatores envolvidos, destaca-se ao entendimento de Educação Física na escola, suas finalidades e objetivos enquanto componente curricular na Educação Básica. Situação essa que parece envolver alunos, direção, comunidade escolar e o próprio professor de Educação Física. Disso decorrem outras implicações como a necessidade de a Educação Física, por meio de seus professores, estabelecer interlocução permanente com as outras áreas do conhecimento presentes no currículo escolar. Sem sombra de dúvida, este distanciamento muito compromete a coparticipação da Educação Física nos projetos educativos de natureza interdisciplinar como é o caso daqueles que buscam abordar o tema transversal meio ambiente, objeto de análise dessa investigação.

Ressalta-se também a necessidade da adoção, por parte dos professores, de abordagens pedagógicas críticas para o ensino dos conteúdos, visando, sobretudo, à articulação entre o aprender a fazer, a saber por que está fazendo e como se relacionar neste fazer, explicitando as dimensões dos conteúdos: conceitual, atitudinal e procedimental. Ainda que tenham se passado mais de três décadas do advento do movimento renovador na Educação Física, cujas proposições tenham repercutido no surgimento de várias propostas metodológicas para o trabalho dos conteúdos da Educação Física na escola, inclusive aquelas de perspectiva crítica de ensino, nota-se que as perspectivas de natureza tecnicista, esportivista e biologicista, parecem predominar no cenário nas escolas de Educação Básica.

A educação ambiental tem-se ancorado, sobretudo, na educação formal, numa perspectiva de transversalidade ou por meio de projetos pedagógicos abertos, através de projetos que possam atingir a comunidade com a finalidade de ampliar o conhecimento das realidades socioambientais dos alunos e que busquem a intervenção e participação na solução de problemas locais e suas múltiplas interações, demandando o trabalho conjunto do coletivo escolar, a fim de integrar esta visão no projeto pedagógico da escola.
Desta forma, parece possível afirmar que, em linhas gerais, a perspectiva transversal e integradora em que a educação ambiental vem se ancorando demanda, de forma precípua e numa mesma ordem de prioridade, abordagens pedagógicas críticas de ensino, bem como interlocução entre as áreas dos saberes que constituem o currículo da Educação Básica.

Destaque ainda deve ser dado à necessidade de o estabelecimento de interfaces entre os conteúdos da Educação Física, aqui ênfase para o esporte de aventura com as questões ambientais que configuram atualmente como um dos grandes problemas da sociedade mundial sem, no entanto, perder de vista o seu papel de integrar o cidadão na esfera da cultura corporal. Tais aspectos se constituem em enormes desafios para os profissionais da referida área do conhecimento.

Sem desconsiderar os descompassos presentes na educação brasileira que se efetivam na realidade concreta da escola, asseveram-se o mérito e a positividade na proposta da Base em incluir o esporte de aventura como um conteúdo nas aulas de Educação Física escolar. Fato que muito poderá contribui com propostas que venham envolver a Educação Física e a dimensão ambiental na escola.

Tendo em vista os resultados apresentados nesta pesquisa, sugerem-se novas investigações sobre o tema, incluindo acompanhamento sistemático de propostas e projetos escolares interdisciplinares que buscam tratar a dimensão ambiental na escola e, ainda, possibilidades de acesso e articulação dos saberes relacionados ao meio ambiente e outros que compõem temas de relevância na sociedade, e seus procedimentos por professores licenciados em Educação Física atuantes na escola.

\section{Notas}

$1 \mathrm{O}$ presente estudo teve como órgão financiador o Conselho Nacional de Desenvolvimento Científico e Tecnológico - CNPQ no período de março de 2015 a fevereiro de 2016.

2 Por Cultura Corporal de Movimento, entende-se o processo de ruptura com a visão biologicistamecanicista do corpo e do movimento situado de forma hegemônica na Educação Física até o início da década de 1980. Trata-se, sobretudo de um conceito que veio representar a dimensão histórico-social ou cultural do corpo e do movimento. (FENSTERSEIFER; GONZÁLEZ, 2005). 


\section{Referências}

ALMEIDA, A. B. et al. Percepção discente sobre a educação física escolar e motivos que levam à sua prática. Revista Mackenzie de Educação Física e Esporte, São Paulo, v. 10, n. 2, p. 109-116, 2011.

BARBOSA, C. L. A. Educação Física Escolar: as representações sociais. Rio de Janeiro: Shape, 2001.

BECKER, H. Métodos de pesquisa em ciências sociais. 2a ${ }^{\text {a }}$ ed. São Paulo: Hucitec. 1994.

BETRÁN, A. O.; BETRÁN J. O. Propuesta de uma clssificación taxonômica de las actividades físicas de aventura em la natureza. Marco conceptual y análisis de los critérios elegidos. Dossier Las Actividades Físicas de Aventura en la Naturaza: análisis sociocultural. Apunts: Educación Física y Deportes, (41), p.108-123, 1995.

BRANDOLIN, F. A percepção dos alunos sobre a Educação Física no Ensino Médio. 2010. 91f. Dissertação (Mestrado em Educação) - Faculdade de Educação, Universidade Federal do Rio de Janeiro - UFRJ, 2010.

BRASIL. Ministério de Educação e do Desporto. Lei de diretrizes e bases da educação nacional. Brasília, MEC, 1996.

. Parâmetros curriculares nacionais: terceiro e quarto ciclos: apresentação dos temas transversais/ Secretaria de Ensino Fundamental. Brasília, MEC/SEF, 1998.

Ministério da Educação. Base Nacional Comum Curricular. Brasília: MEC, 2017.

BRUHNS, H. T. No ritmo da aventura: explorando sensações e emoções. In.: MARINHO, A.; BRUHNS. H. T. Turismo, lazer e natureza. São Paulo: Manole, 2003.

COLL, C.; POZO, J. I.; SARABIA, B.; VALLS, E. Conteúdos na reforma: ensino e aprendizagem de conceitos, procedimentos e atitudes. $1^{\mathrm{a}}$ edição. Artmed: Porto Alegre, 2000.

COSTA, V. L. M. Esportes de aventura e risco calculado na montanha: um mergulho no imaginário. $1^{a}$ edição. São Paulo: Manole, 2000.
DARIDO, S. C.; RANGEL, I. C. A. Educação

Física na escola: implicações para a prática pedagógica. $1^{\text {a }}$ edição. Rio de Janeiro: Guanabara Koogan, 2005.

DARIDO, S. C. et al. A Educação Física, a formação do cidadão e os Parâmetros Curriculares Nacionais. Revista Paulista de Educação Física, São Paulo, v.15 (1), p.17-32, jan./jun. 2001.

FEHRING, R. J. Methods to validate nursing diagnoses. Heart Lung, England, v. 16, n. 6, p. 625629, November/1987.

FENSTERSEIFER, P. E.; GONZÁLEZ, F. J. (Orgs.). Dicionário Crítico de Educação Física. $1^{\mathrm{a}}$ edição. Ijuí: Ed. Unijuí, 2005.

GONZÁLEZ, F. J.; FENSTERSEIFER, P. E. Entre o "não mais" e o "ainda não": pensando saídas do não-lugar da Educação Física escolar I. Cadernos de Formação RBCE, p. 9-24, set. 2009.

GHIRALDELLI JUNIOR, P. Educação física progressista: a pedagogia critico-social dos conteúdos e a educação física brasileira. $10^{\mathrm{a}}$ ed. São Paulo: Edições Loyola, 2007.

GUATTARI, F. As três ecologias. $17^{\mathrm{a}} \mathrm{ed}$. Campinas, SP: Papiros, 2006.

GUIMARÃES, S. S. M. et al. Educação física no ensino médio e as discussões sobre meio ambiente: um encontro necessário. Revista Brasileira de Ciências do Esporte, Campinas, v. 28, n. 3, p. 157172, maio 2007.

HILDEBRANDT-STRAMANN, R. Educação Física aberta à experiência: uma concepção didática em discussão. $1^{\text {a }}$ edição. Rio de Janeiro: Imperial Novo Milênio, 2009.

KUNZ, E. Transformação didático-pedagógica do esporte, $5^{\text {a }}$ ed. Ijuí: Unijuí, 2003.

LEFF, E. Sobre la formación del saber ambiental em formación ambiental. México: PNUMA, 1991.

MEDINA, N. M. A formação de professores em educação ambiental. Oficina de Trabalho, COEA/MEC. Março, 2000.

MEDINA, N. M.; SANTOS, E. C. Educação 
ambiental: uma metodologia participativa de formação. $1^{a}$ edição. Rio de Janeiro: Vozes, 1999.

NOVO, M. Pedagogia ambiental. Madri: Ed. Fundación Universidad-Empresa, 1989.

PAIVA, A. C.; FRANÇA, T. L. Trilhas interpretativas: reconhecendo os elos com a Educação Física. Revista Brasileira de Ciências do Esporte, Campinas, v. 28, n. 3, p.109-124, 2007.

PAIXÃO, J. A. et al. Risco e aventura no esporte na percepção do instrutor. Psicologia \& Sociedade, Belo Horizonte, 23 (2), p. 415-425, 2011.

PAIXÃO, J. A. O instrutor de esporte de aventura no Brasil e os saberes necessários a sua atuação profissional. $1^{\text {a }}$ edição. Curitiba, PR: CRV, 2012.

PEREIRA, D. W.; CARVALHO, G. S.; RICHTER, F. Programa de escalada em rocha como Educação Física para alunos do ensino médio. In: FONTOURA, P. (Org.). Pesquisa em Educação Física. Jundiaí: Fontoura, 2008. v. 7. p. 397-402.

SOARES, C. L. et al. Metodologia do ensino de educação física. $1^{a}$ edição. São Paulo: Cortez, 1992.

SOARES, C. J. S.; PAIXÃO, J. A. Atividades de aventura e educação ambiental: possibilidades nas aulas de educação física escolar. Lecturas: educación física y deportes, Buenos Aires, v. 142, p. 1-1, 2010. Disponível em: http://www.efdeportes.com/efd142/atividades-deaventura-e-educacao-ambiental.htm. Acesso em: 05 agosto 2016.

SOARES, M. G. Três décadas de movimento renovador da Educação Física: alcançamos a maioridade epistemológica? Conexões - Revista da Faculdade de Educação Física da UNICAMP, Campinas, v. 8, n. 3, p. 24-34, set./dez. 2010.

TAHARA, A. K.; CARNICELLI FILHO, S. A presença das atividades de aventura nas aulas de Educação Física. Arquivos de Ciências do Esporte, Uberaba, v. 1, n. 1, p. 60-66, 2013.

TAHARA, A. K.; DARIDO, S. C. Práticas corporais de aventura em aulas de Educação Física na escola. Conexões - Revista da Faculdade de Educação Física da UNICAMP, Campinas, SP v. 14 n. 2 p. $113-136$ abr./jun. 2016.

THOMAS, J. R.; NELSON, J. K.; SILVERMAN, S. J. Métodos de pesquisa em atividade física. 6. ed. Porto Alegre: Artmed, 2012.

YUS, R. Temas transversais: em busca de uma nova escola. $1^{a}$ edição. Porto Alegre: ArtMed, 1998.

\section{Sobre o autor}

Jairo Antônio da Paixão é Professor do Curso de Licenciatura em Educação Física da Universidade Federal de Viçosa (UFV). Coordenador do Grupo de Pesquisa e Estudos Pedagógicos em Educação Física (GEPEF). Docente do Programa de Pós-Graduação em Educação (PPGE/UFV).

Recebido em março de 2017. Aprovado em novembro de 2017. 